Acta Horticulturae et Regiotecturae 1

Nitra, Slovaca Universitas Agriculturae Nitriae, 2016, pp. 17-20

\title{
EFFECTS OF SALINITY AND PLANT GROWTH MEDIA ON IN VITRO GROWTH AND DEVELOPMENT OF TARO (COLOCASIA ESCULENTA L.) VARIETIES
}

\author{
Varea VAURASI, Rashmi KANT* \\ School of Agriculture and Food Technology, University of the South Pacific - Samoa
}

\begin{abstract}
Taro Colocasia esculenta is a staple food in most countries of the South Pacific region. However, the recent changes in the climatic conditions and the associated factors became a threat to growing taro in the region. Rising sea level and frequent dry and wet conditions had led to increased soil salinity which is a limiting factor in producing taro in these atoll islands. The aim of this research was to screen selected taro varieties based on their ability to tolerate salinity conditions in Samoa. Effects of three salinity levels ( 0.2 , $3 \%$ and $5 \%$ ), and growth hormones Benzylaminopurine (BAP) and Thidiazuron (TDZ) were examined on growth and development of in vitro grown taro varieties. Plant height, number of leaves, and number of roots produced were compared in the selected varieties. Results suggest that all varieties had callus induction and regeneration in MSO medium. Addition of BAP induced better growth and the plants produced higher number of leaves, while TDZ improved roots proliferation in C. esculenta. Solomon variety performed best in high salinity conditions. Samoa- 1 grew taller and had more leaves and roots compared to Samoa- 2 variety. Thus, we suggest Solomon and Samoa-1 could perform better in high-salinity conditions.
\end{abstract}

Keywords: Taro, salt tolerance, climate change, in vitro screening, taro leaf blight

Taro (Colocasiae esculenta) is one of the important root crops grown throughout the tropical and subtropical regions. This crop remained a staple food for most countries of the south Pacific region including Fiji, Cook Island, Tonga, the Solomon Islands, PNG and Samoa (losefa et al., 2012). The corm of C. esculenta is an excellent source of energy, fibre and nutrients such as calcium and iron. The leaves are excellent source of protein, dietary fibre and wide range of vitamins and minerals including carotene, potassium, calcium, phosphorous, iron, riboflavin, thiamine, niacin, vitamin A and vitamin C (Hunter et al., 2000). It is also considered a prestige crop for traditional feasts, gifts and fulfilling social obligations in the region.

Despite several pest and disease epidemics, this crop remained the favourite food of the region. Currently, Fiji is the major producer and exporter of $C$. esculenta in the region. The Taro leaf blight (TLB) Phytopthora colocasiae epidemic in 1993 devastated the taro industry in Samoa and since then Samoa is struggling to re-establish its taro export market (Hunter et al., 2000; losefa et al., 2012). Samoan government in partnership with several organisations including the Australian Centre for International Agricultural Research (ACIAR), Australia developed and released TLB resistant varieties of C. esculenta. Among the released varieties, Samoa-1 and Samoa-2 are the preferred varieties for local consumption and export market (losefa et al., 2012).

Recent research on the weather pattern suggests that the South Pacific region is highly vulnerable to extreme weather conditions (Barnett, 2011). Agriculture of Samoa and other countries of the region is vulnerable to coastal inundation and extreme rain fall pattern that led to high soil salinity conditions (Barnett, 2011). Abiotic stress is created by combination of water deficiency and Sodium toxicity due to sodium and chloride and creates negative effects on development of the plant (Munns, 2002). Plants can tolerate high salt concentration by withstanding the adverse water relations induced by salinity or decreasing the movement of toxic ions to the shoots (Munns and Tester, 2008).

Colocasia esculenta is a perennial herb of Aracea family that can grow up to 1-2 meters high. Depending on the type of variety, it takes 6-12 months before taro can be harvested. It is generally grown in wet, humid environment and requires a rainfall of over $2000 \mathrm{~mm} /$ year but can still tolerate lower rainfall (Hunter et al., 2000). It is generally grown as a mono crop in Samoa, however, it can be grown in multiple cropping systems with other root crops such as cassava, yam and prefers soils with $\mathrm{pH}$ 5.6-6.5.

C. esculenta is highly susceptible to cyclones, flooding and cannot tolerate high salinity conditions and such climatic conditions create stress which could lead to vulnerability pest and disease attack (Barnett, 2011; Kant et al., 2015). These constraining factors warrant the conservation of the taro genetic material for future generations and the development of pre-screening methods for salt tolerant varieties (Munns and Tester, 2008). The availability of salt tolerant cultivars requires efficient rapid multiplication techniques to enable effective distribution of planting material to the farmers for backup. Tissue culture can effectively be used in the rapid screening and multiplication of plants (Chand and Pearson, 1998). The aim of this research was to screen selected C. esculenta varieties, two highly resistant TLB cultivars and Solomon and Indonesian cultivars for salinity tolerance 
by assessing their growth and development in in vitro conditions, and also, how growth hormones TDZ and BAP affect the performance of these varieties.

\section{Material and methods}

\section{Experimental site and planting materials}

The study was conducted at the Tissue Culture laboratory, University of the South Pacific, Alafua, Samoa. Four varieties of $C$. esculenta were selected to examine the effects of salinity levels and growth hormones on their growth and development (Table 1). Recently, Samoa-1 and Samoa-2 are the main varieties released by the Ministry of Agriculture and Fisheries (MAF), Samoa against the Taro Leaf Blight (TLB). Both varieties are grown for local consumption and export market. The planting materials for Samoa-1 and Samoa- 2 were procured from the Nuu Research Station of MAF while the other two varieties Solomon and Indonesia were obtained from the USP Tissue Culture laboratory.

\section{Preparing explants for experiment}

Experimental plants were trimmed down to small plantlets to small headsets of about $1 \mathrm{~cm}$ long, with small segments of the basal corms attached. Taro explants were sterilised by soaking in $20 \%$ Chlorox solution ( $8.25 \%$ Sodium hypochlorite) for 15 minutes. The plants were then dipped in $70 \%$ ethanol for 2 minutes and finally the plants washed/ rinsed thoroughly with sterile distilled water to get rid of Chlorox residues from the plants. The tools used including scalpel blades, forceps and tiles were sterilised overnight in a hot air oven at $160^{\circ} \mathrm{C}$, and during the inoculation, ethanol and a hot bead steriliser were used to achieve aseptic conditions.

\section{Plant growth media and growth hormone}

The basal culture medium Murashige and Skoog 1962"MSO" with the $3 \%$ sucrose was used for callus initiation. The media were solidified with Gelrite $\left(1.75 \mathrm{~g} \mathrm{l}^{-1}\right)$ with a $\mathrm{pH} 5.6+0.1$. The media were dispensed in small glass tubes where lids are loosely tightened before autoclaving for 15 minutes at $121 \mathrm{psi}$. The shoot tips of the explants were then inoculated on taro growth media (MSO) under laminar air flow system and the explants were incubated at $23 \pm 2^{\circ} \mathrm{C}$ and $12 \mathrm{~h}$ photoperiod. Later the basal culture medium was supplemented with $1 \mathrm{mg}$ $\mathrm{I}^{-1} \mathrm{BAP}$ and $1 \mathrm{mg} \mathrm{l}^{-1}$ TDZ separately. The concentration was kept $1 \mathrm{mg} \mathrm{l}^{-1}$ to avoid excessive callusing (Du et al., 2006; Nyman et al., 1983). Each treatment including the control was replicated fifteen times. The data on growth and development of plants were collected after 4-5 weeks periods.

\section{Salt treatments}

Two salt treatments were tested and compared with control (plants grown in MSO). pH and electrical conductivity of the three solutions is presented in Table 1. The parameters were measured at $23^{\circ} \mathrm{C}$ and the required salt solutions were added directly in the plant culture medium. The electrical conductivity and $\mathrm{pH}$ in each treatment were measured (Table 2). Data on plant growth and development were quantified by measuring plant height and counting the leaf and root numbers.

\section{Statistical analysis}

The data on plant height, leaf number, number of suckers were analysed using analysis of variance (ANOVA). The means were compared using the Tukey's studentized test. Regression was carried out to understand the relationship between plant height and number of leaves and number of roots. Statistical software Minitab- 17 was used for all analyses, and were carried out with $\alpha=5 \%$ level of significance.

\section{Results and discussion}

\section{Growth and development of C. esculenta in MSO medium and growth hormones}

All four selected varieties were able to grow in the MSO medium. Plant growth substantially enhanced on addition of growth hormones ( $F=3.44, p=0.018$ ) (Figure 1). The greatest effect of hormone was found in Indonesian variety

Table 1 Characteristics of Colocasia esculenta varieties used in this study. Taro accession no was received from MAF laboratory

\begin{tabular}{|l|c|c|c|c|}
\hline No & $\begin{array}{c}\text { Taro varieties } \\
\text { accession no }\end{array}$ & $\begin{array}{c}\text { Referred } \\
\text { in this research }\end{array}$ & $\begin{array}{c}\text { Country } \\
\text { of Origin }\end{array}$ & $\begin{array}{c}\text { Characteristics of different } \\
\text { varieties }\end{array}$ \\
\hline $\mathbf{1}$ & 017 & Samoa-1 & Samoa & $\begin{array}{c}\text { - leaves are heart- shaped, pointed tip and striped yellow; petioles are } \\
\text { greener and thick; roots are thick with many root hairs; branched }\end{array}$ \\
\hline $\mathbf{2}$ & 026 & Samoa-2 & Samoa & $\begin{array}{c}- \text { leaves are heart shaped and lighter in colour; petioles are maroon in } \\
\text { colour; roots are lighter green }\end{array}$ \\
\hline $\mathbf{3}$ & 033 & Solomon & Solomon & $\begin{array}{c}\text { - leaves are heart shaped but sort of oval; roots are lighter green; petioles } \\
\text { are lighter green }\end{array}$ \\
\hline $\mathbf{4}$ & 024 & Indonesian & Indonesia & $\begin{array}{c}\text { - leaves are heart shaped with curved edges and side leaves were } \\
\text { yellowish; roots were lighter green }\end{array}$ \\
\hline
\end{tabular}

Table 2 Electrical conductivity $(\mathrm{EC})$ and $\mathrm{pH}$ of the media in the salinity treatments used in the experiments

\begin{tabular}{|l|c|c|}
\hline Salt concentration (Salinity) & Electrical conductivity in $\mathbf{~ S \mathbf { c m } ^ { - 1 }}$ & $\mathbf{p H}$ \\
\hline Normal (no salt added) & 2.0 & 6.8 \\
\hline $\mathbf{3} \% \mathbf{~ N a C l}$ & 20.53 & 7.2 \\
\hline $\mathbf{5} \% \mathbf{~ N a C l}$ & 37.24 & 8.3 \\
\hline
\end{tabular}




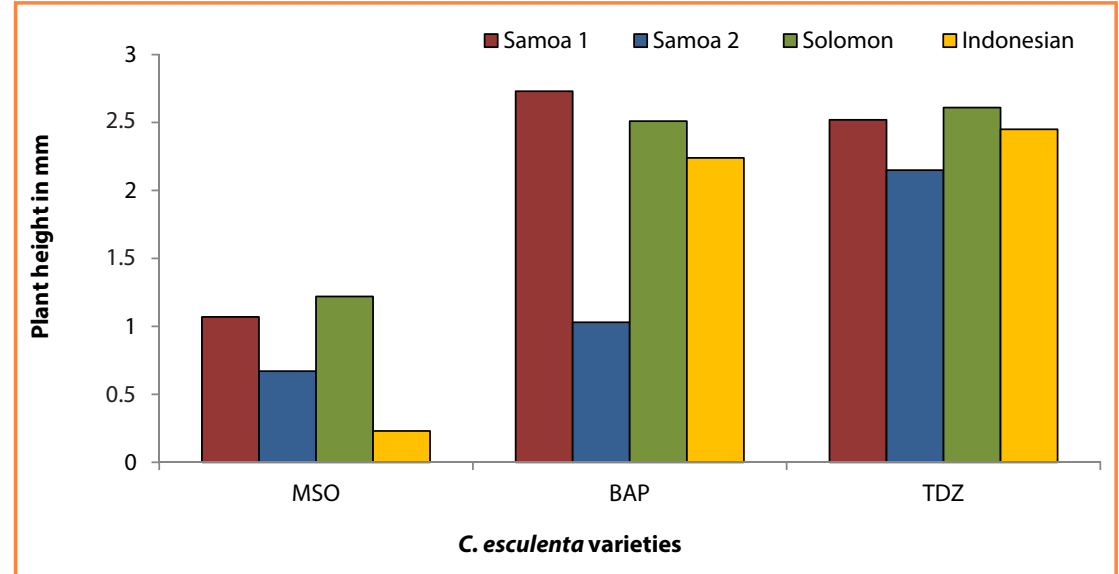

Figure 1 Effects of two plant growth hormones, Benzylaminopurine (BAP) and Thidiazuron (TDZ), on shoot growth of the four selected Colocasia esculenta varieties. Mean $( \pm \mathrm{SE})$ plant height $(\mathrm{mm})$ of the in vitro grown plants

that grew almost 10 times taller when MSO medium was fortified with hormones. There was no significant difference in the plant heights of the four varieties grown in the presence of TDZ ( $F=0.46, p=0.71)$. However, Samoa 1 performed better than Samoa 2 in BAP $(F=5.07, p=0.004$; Figure 1). This suggests that the MSO media have enough nutrients that are required to support the growth of C. esculenta plants (Chand and Pearson, 1998; Du et al., 2006).

Overall, both medium improved the number of leaves $(F=11.95, p<0.001)$, and the number of roots $(F=20.98$, $p<0.001)$. However, asymmetric effects of growth hormones on leaf and root generation were found among the varieties (Table 3). When grown in MSO medium, the mean number of leaves produced by the Indonesian variety was lower than the other three varieties (Sama et al., 2012). However, addition of either TDZ or BAP significantly increased the leaf production in Solomon and Indonesian varieties. There was no difference in the number of leaves produced by Samoa-1 and Samoa-2 when grown in BAP. However Samoa-2 excel when grown in TDZ (Table 3). In terms of root development, the Solomon variety performed best after addition of growth hormone. Samoa-1 produced more roots in both growth hormones, whereas Samoa-2 performed only in TDZ but MSO (Table 3). Root initiation occurred better in BAP than TDZ in C. esculenta (Du et al., 2006). However, the shoot development and leaf number was higher in TDZ than BAP. Activities plants. Error bars indicates SE of TDZ are generally similar to cytokinin that helps in shoot generation and leaf production (Chand and Pearson, 1998; Sama et al., 2012). However, Samoa-2 probably needs fortification of plant nutrients for its development.

\section{Effects of salinity treatments on Growth and development of the four varieties}

Increase in salinity drastically reduced the growth of the Samoa-1 and Samoa-2 varieties, however, no significant changes in the plant heights of the Solomon and Indonesian varieties were observed $(F=4.71, p<0.05)$. Growth of the Samoa- 1 plants was much better than the Samoa-2 plants $(F=8.92$, $p<0.001$; Figure 2). The effects of salinity on taro growth is not well known, however the variability in tolerance within the aroid genera and genus Colocasia (Chang et al., 1984). Samoa-2 possibly susceptible to osmotic toxicity that reduces the plant growth in saline conditions (Munns and Tester, 2008).

The number of leaves and roots produced by Samoa-1 and Samoa-2 varieties were adversely affected when grown in saline conditions. The effects

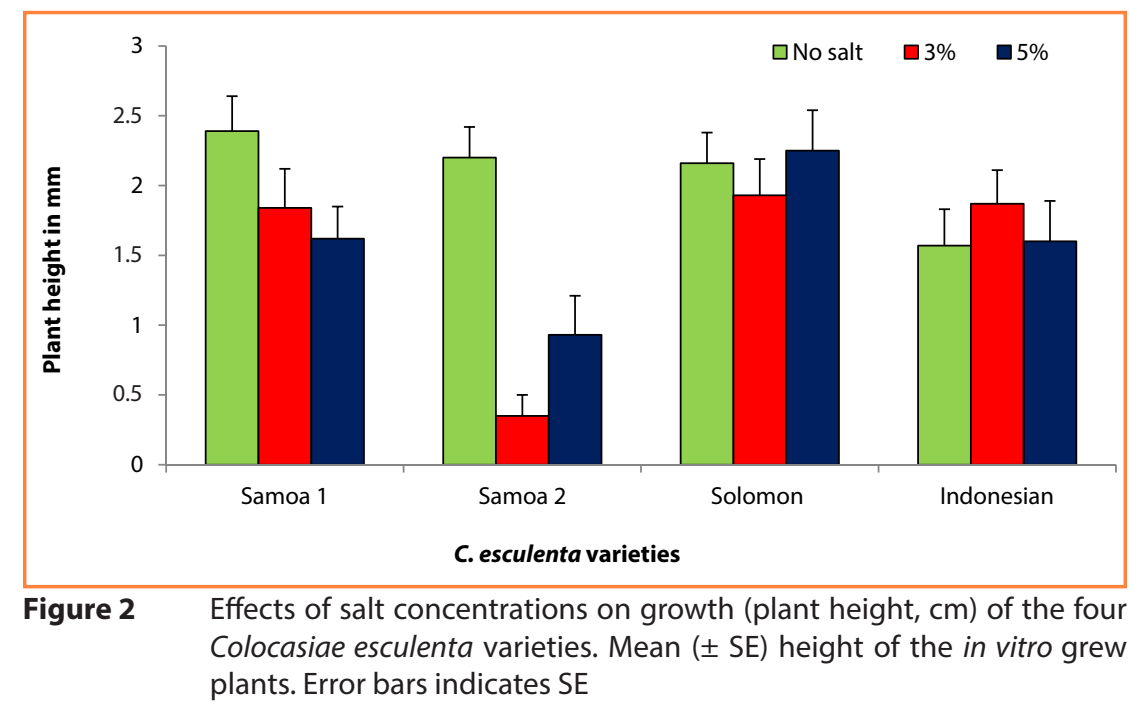

Figure 2 Effects of salt concentrations on growth (plant height, $\mathrm{cm}$ ) of the four Colocasiae esculenta varieties. Mean ( $\pm \mathrm{SE}$ ) height of the in vitro grew

Table 3 Effects of two plant growth hormones, Benzylaminopurine (BAP) and Thidiazuron (TDZ), on leaf and root formation of the four selected Colocasiae esculenta varieties. Mean $( \pm$ SE) number of leaves and roots of the in vitro grown plants

\begin{tabular}{|l|c|c|c|c|c|c|}
\hline \multirow{2}{*}{ Taro varieties } & \multicolumn{3}{|c|}{ Number of leaves } & \multicolumn{3}{c|}{ Number of roots } \\
\cline { 2 - 7 } & \multicolumn{2}{|c|}{ growth medium and hormone } & \multicolumn{2}{c|}{ growth medium and hormone } \\
\cline { 2 - 7 } & MSO only & MSO + BAP & MSO + TDZ & MSO only & MSO + BAP & MSO + TDZ \\
\hline Samoa 1 & $0.8 \pm 0.45$ & $1.1 \pm 0.16$ & $0.93 \pm 0.18$ & $1.46 \pm 0.51$ & $2.33 \pm 0.31$ & $2.2 \pm 0.27$ \\
\hline Samoa 2 & $1.7 \pm 0.28$ & $1.33 \pm 0.31$ & $1.73 \pm 0.18$ & $0.73 \pm 0.41$ & $1.27 \pm 0.33$ & $2.6 \pm 0.48$ \\
\hline Solomon & $1.4 \pm 0.27$ & $2.87 \pm 0.32$ & $2.47 \pm 0.25$ & $1.0 \pm 0.48$ & $3.73 \pm 0.47$ & $3.4 \pm 0.4$ \\
\hline Indonesian & $0.4 \pm 0.23$ & $3.26 \pm 0.38$ & $2.67 \pm 0.35$ & $0.53 \pm 0.35$ & $3.2 \pm 0.41$ & $2.33 \pm 0.38$ \\
\hline
\end{tabular}


Table 4

Effects of salinity levels on leaf and root development of four selected Colocasiae esculenta varieties. Mean ( \pm SE) number of leaves and roots of the in vitro grown plants of the different varieties

\begin{tabular}{|c|c|c|c|c|c|c|}
\hline \multirow[t]{3}{*}{ Taro varieties } & \multicolumn{3}{|c|}{ Number of leaves } & \multicolumn{3}{|c|}{ Number of roots } \\
\hline & \multicolumn{3}{|c|}{ salinity levels } & \multicolumn{3}{|c|}{ salinity levels } \\
\hline & no salt & $3 \%$ & $5 \%$ & no salt & $3 \%$ & $5 \%$ \\
\hline Samoa 1 & $2.3 \pm 0.22$ & $1.10 \pm 0.16$ & $0.6 \pm 0.13$ & $2.8 \pm 0.22$ & $1.67 \pm 0.32$ & $1.53 \pm 0.32$ \\
\hline Samoa 2 & $2.0 \pm 0.25$ & $0.53 \pm 0.19$ & $0.36 \pm 0.17$ & $1.93 \pm 0.26$ & $0.67 \pm 0.18$ & $0.82 \pm 0.48$ \\
\hline Solomon & $2.1 \pm 0.27$ & $2.67 \pm 0.24$ & $2.07 \pm 0.24$ & $2.93 \pm 0.27$ & $2.03 \pm 0.42$ & $2.67 \pm 0.49$ \\
\hline Indonesian & $1.87 \pm .23$ & $3.20 \pm 0.38$ & $1.27 \pm 0.30$ & $1.8 \pm 0.35$ & $2.33 \pm 0.32$ & $1.63 \pm 0.26$ \\
\hline
\end{tabular}

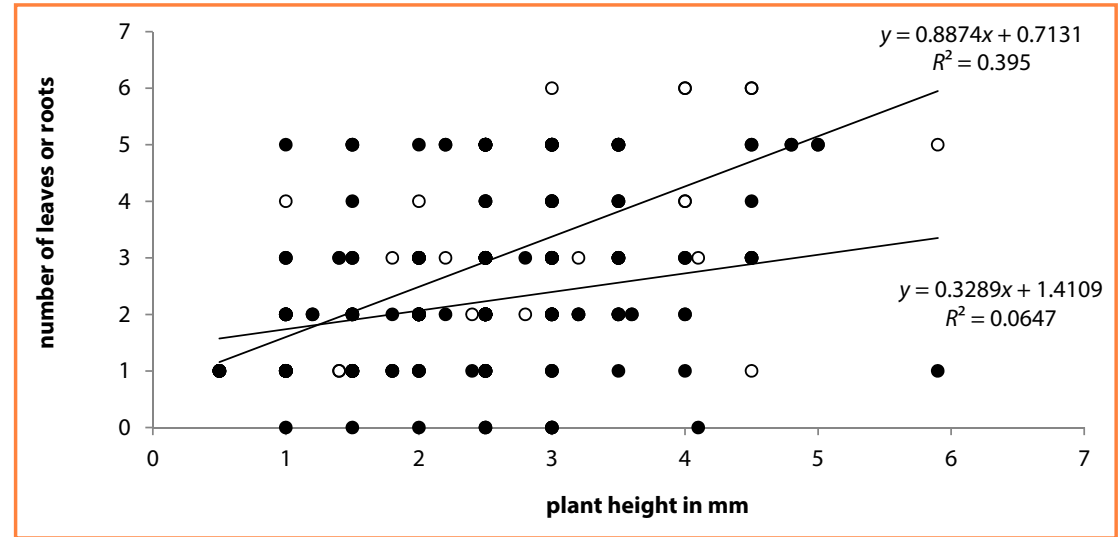

Figure $3 \quad$ Relationship between plant height and number of leaves and number of roots developed in the Colocasia esculenta varieties

were more pronounced on Samoa-2 than Samoa-1 (Table 4). Solomon and Indonesian varieties performed best at $3 \%$ salinity. Very high salinity $(5 \%)$ negatively affected the leaf production in Indonesian but in Solomon variety $(F=4, p=0.001)$. Salinity had adverse effects on rooting in Samoa-1 and Samoa-2 but the effect was not profound in Solomon and Indonesian varieties $(F=4.05, p=0.019)$. Higher salinity did not affect the production of roots in Solomon and Indonesian varieties (Table 4). Chand and Pearson (1998) found that salinity generally reduces growth rate resulting in smaller leaves, shorter stature and fewer leaves. Encrustation of salt exudates on the plants suggests the ability of $C$. esculenta to withstand the salinity; however, this is not uniform in all varieties (Munns and Tester, 2008). The plants that could not cope with the higher salinity conditions had their leaves turned yellow which started near the veins and spread toward edge or tip of the leaf. The older leaves died before younger ones (Munns, 2002).

Plant height and root formation has positive interaction as results of growing C. esculenta varieties ( $F=74.24$, $p<0.001$; Fig 3). However, plant height and number of leaves produced show a weak relationship ( $F=8.5, p<0.01$; Fig 3). This suggests that the leaf and shoot developments are independently controlled by nutrients and plant hormones (Munns and Tester, 2008).

\section{Conclusion} under control condition (no salt stress) all the four varieties of $C$. esculenta had callus induction and regeneration in MSO medium. Overall, growth and development of $C$. esculenta varieties performed better in BAP than TDZ hormone. In particular, root initiation occurred better in BAP while shoot development and leaf number was higher in TDZ than BAP. The Solomon variety performed best in saline conditions. Samoa-1 grew taller and compared to Samoa-2 variety. Thus, we suggest Solomon in general and Samoa-1 particular in Samoa (due to TLB presence) could perform better in high-salinity conditions.

\section{References}

BARNETT, J. 2011. Dangerous climate change in the Pacific Islands: food
For our study, it can be concluded that had more number of leaves and roots production and food security. Regional Environmental Change, no. 11, pp. 229-237. CHAND, H. - PEARSON, MN. 1998. Rapid vegetative multiplication in Colocasia esculenta (L) Schott (taro). Plant Cell, Tissue and Organ Culture, 1998. no. 55, pp. 223-226. CHANG, H. - SIEGEL, BZ. - SIEGEL, SM. 1984. Salinity-induced changes in isoperoxidases in taro Colocasia esculenta. In Phytochemistry, 1984, no. 23, pp. 233-235.

DU, HM. - TANG, DM. - HUANG, DF. 2006. Fragrant taro'[Colocasia esculenta (L.) Schott var. Antiquorum] micropropagation using thidiazuron and benzylaminopurine. In Journal of Horticultural Science \& Biotechnology, 2006, no. 81, pp. 379-384. HUNTER, DG. - IOSEFA, T. - CHARLES, JD. FONOTI, P. 2000. Beyond taro leaf blight: a participatory approach for plant breeding and selection for taro improvement in Samoa. Proceedings of the International Symposium on Participatory Plant Breeding and Participatory Plant Genetic Resource Enhancement, 2000. pp. 1-5.

IOSEFA, T. - Taylor, M. - Hunter, D. - TUIA, VS. 2012. The taro improvement program in Samoa: sharing genetic resources through networking. FAO RAP-NIAS Plant Genetic Resources in Asia and the Pacific: Impacts and Future Directions, 2012. pp. 25-40.

KANT, R. - PRASAD, A. - NANDANI, P. 2015. Feeding strategies of Taro aphid Aphis gossypii on selected varieties of Taro Colocasia esculenta in Samoa. In Journal of Economic Entomology (Under publication). MUNNS, R. 2002. Comparative physiology of salt and water stress. In Plant, Cell \& Environment, 2002, no. 25, pp. 239-250.

MUNNS, R. - TESTER M. 2008. Mechanisms of salinity tolerance. In Annu. Rev. Plant Biol., 2008, no. 59, pp. 651-681.

NYMAN, LP. - GONZALES, CJ. - ARDITTI, J. 1983. In vitro selection for salt tolerance of taro (Colocasia esculenta var antiquorum). In Annals of Botany, 1983, no. 51, pp. 229-236. SAMA, AE. - HUGHES, HG. - ABBAS, MS. - SHAHBA, MA. 2012. An efficient in vitro propagation protocol of cocoyam [Xanthosoma sagittifolium (L) Schott]. In The Scientific World Journal Article ID 346595, 2012, pp. 1-10. 